\title{
Reproductive behaviour of families segregating for Cooley's anaemia before and after the availability of prenatal diagnosis
}

\author{
Maria Rita Gamberini, Marco Lucci, Calogero Vullo, Barbara Anderson, Rita Canella, Italo Barrai
}

\begin{abstract}
The reproductive behaviour of couples with heterozygous $\beta$ thalassaemia, with at least one affected child, was investigated for the period 1955 to 1984 and was compared to the behaviour of control couples matched for age, age at marriage, and presence of at least one child. The comparisons were made as a function of knowledge of the risk and availablility of prenatal diagnosis and abortion. It was found that the couples segregating for Cooley's anaemia, before knowledge of the risk, had a higher reproductive rate than that of control couples. Knowledge of the genetic risk had a different effect on reproductive behaviour in the 1950s from that in later years. The difference was attributed both to the influence of cultural factors and to technical, therapeutic, and diagnostic advances.
\end{abstract}

Cooley's anaemia, or $\beta$ thalassaemia major, is a severe, chronic anaemia caused by homozygosity for alleles responsible for the decrease or absence of haemoglobin $\beta$ chain production. If untreated, it leads to death between the second and sixth year of life, depending on the severity of the anaemia. Treatment, which has been available for several decades, consists of regular blood transfusions. It has been more successful since the introduction of intensive iron chelation by subcutaneous infusion of desferrioxamine. A patient's life span is now increased to three or four decades. ${ }^{2}$

The $\beta$ thalassaemias are transmitted as Mendelian autosomal recessive alleles, ${ }^{3}$ so that the risk of having a child with Cooley's anaemia is $\mathbf{1}$ in $\mathbf{4}$ for couples who are both carriers. Genetic counselling is advantageous

Pediatric Division, USL 31, Ferrara, Italy.

M R Gamberini, M Lucci, C Vullo, B Anderson Institute of Zoology, University of Ferrara, Via Borsari 46, 44100 Ferrara, Italy.

R Canella, I Barrai

Correspondence to Professor Barrai.

Received for publication 10 July 1990

Revised version accepted for publication 31 January 1991. as this is a clear cut Mendelian trait where the heterozygote can be distinguished from both homozygotes.

The purpose of genetic counselling is to give a couple who are both carriers information on the genetic risk of producing an affected child, so that they may choose a course of action aimed at avoiding the possibility of producing such a child. The effect of the genetic risk on the reproductive behaviour of thalassaemic couples may be conditioned by several factors, such as a previous affected child, the cultural level of the couple, the family size desired, the availability of prenatal diagnosis, and the acceptance of abortion. ${ }^{4}$ Such factors will depend on changing cultural trends, and may result in different types of reproductive behaviour. For example, Aguzzi et al; ${ }^{5}$ using data collected in 1974, showed the presence of reproductive compensation in a group of families segregating for Cooley's anaemia in the population of the Po Delta.

Reproductive compensation is not a general phenomenon in industrialised countries and, therefore, because of the important social, economic, and demographic changes which took place in the Po Delta area between 1974 and 1984, we thought that it would be useful to re-examine the reproductive behaviour of a similar group of families in this area before and after availability of prenatal diagnosis.

\section{Subjects and methods}

We studied the reproductive behaviour of 123 thalassaemic families who had children with Cooley's anaemia. They were included consecutively in the study as they presented at our centre for transfusion therapy of the affected child.

The following data were collected by interviewing one member of each couple: dates of birth of husband and wife and of affected and normal children; the year when the parents were made aware of the genetic risk and were informed of the availability of prenatal diagnosis; the number of voluntary abortions; and reasons for non-acceptance of prenatal diagnosis.

Each marriage was divided into four phases up to January 1984, according to the criteria used by Modell et al, ${ }^{6}$ relating both to knowledge of the risk of 
Table 1 The phases of awareness of genetic risk and availability of courses of action for couples in the study.

\section{Marriage}

Phase 1

Awareness of risk

Phase 2

Prenatal diagnosis available

Phase 3

Phase 4

Awareness of risk simultaneous with availablity of prenatal diagnosis

producing a child with homozygous thalassaemia and to availability of prenatal diagnosis. The phases were as follows.

Phase 1. Couple did not know risk (from date of marriage to knowledge of risk to couple).

Phase 2. Couple knew risk but prenatal diagnosis was not available (from discovery of risk to availability of prenatal diagnosis).

Phase 3. Couple knew risk and prenatal diagnosis was available (from availability of prenatal diagnosis to time of study).

Phase 4. Couple did not know risk when discovered during pregnancy, with prenatal diagnosis as an option (from date of marriage to knowledge of risk; subsequent years counted as phase 3 ).

Table 1 illustrates the various phases in the marriage through which the couples might pass. We considered that the reproductive life of couples ended when the wife reached 44 years, because after this age the percentage of births in the general population is negligible $(0 \cdot 17 \%$ in 1983$) .^{7}$

The mean age of parents, the mean duration of marriage, the numbers of normal and affected children, of voluntary abortions, of prenatal diagnoses performed, and of abortions requested after prenatal diagnosis, were analysed for every phase, and the following indices were calculated: years of marriage per child, percent of abortions, and percent of healthy children.

We also studied 114 control couples obtained through the Central Registry Office of the Ferrara Municipality. For each thalassaemic couple, a control couple with at least one child was selected, and with approximately similar dates of birth and marriage. The marriage was then divided into periods equal to the phases in the marriage of the thalassaemic couple with whom the control couple was matched. For each phase considered, the sum of years of marriage was divided by the sum of living children for (1) all thalassaemic couples and (2) all control couples who went through that particular phase, and an index was obtained for (1) and (2) in every phase, which we define as the years of marriage per living child (YMC). In practice, this index indicates the time necessary to produce one child in a particular phase of marriage $(1,2,3$, and 4$)$. If the index is low, it indicates that there was high reproductivity, and vice versa.

We thought it acceptable to assume that the number of living children of control couples was the same as the number of births, because child mortality was not expected to be different from that of the regional population, that is less than $1 \%(0.95 \%$ for the Emilia Romagna Region, ISTAT 1985). In the 123 thalassaemic couples the deaths of nine out of 225 children were all the result of clinical complications of Cooley's anaemia.

Some variables which might affect fertility were considered in the thalassaemic and control couples (table 2). The two groups were not different in any of the variables, and therefore their reproductive behaviour can be compared directly and any difference can be attributed to factors other than age, duration of marriage, or different fertility.

\section{Results}

The 123 thalassaemic couples were divided into six groups, depending on the combination of phases through which they passed:

$\begin{array}{llc}\text { Group } & \text { Phase } & \begin{array}{c}\text { No } \\ \text { of couples }\end{array} \\ 1 & 1+2 & 14 \\ 2 & 1+2+3 & 84 \\ 3 & 1+3 & 11 \\ 4 & 2+3 & 10 \\ 5 & 3+4 & 3 \\ 6 & 3 & 1\end{array}$

In group 1, the women were 44 years old before 1978 when prenatal diagnosis became available.

COUPLES WHO WENT THROUGH PHASES 1 AND 2 (14 COUPLES)

The oldest couples belong to this group. The mean year of marriage was 1955 . In phase 1 there is no

Table 2 Statistics of demographic variables.

\begin{tabular}{|c|c|c|c|c|c|}
\hline & \multicolumn{2}{|c|}{$\begin{array}{l}\text { Age at } \\
\text { marriage }\end{array}$} & \multirow{2}{*}{$\begin{array}{c}\begin{array}{c}\text { Age } \\
\text { difference }\end{array} \\
H-W\end{array}$} & \multirow{2}{*}{$\begin{array}{c}\begin{array}{c}\text { Age at birth of } \\
\text { first child }\end{array} \\
W\end{array}$} & \multirow{2}{*}{$\begin{array}{c}\text { Duration } \\
\text { of marriage } \\
\text { at } 1.1 .84\end{array}$} \\
\hline & Wife & Husband & & & \\
\hline $\begin{array}{l}\text { Control } \\
\text { Thalassaemic } \\
t\end{array}$ & $\begin{array}{l}21 \cdot 67 \\
21 \cdot 95 \\
0 \cdot 577 \\
\text { NS }\end{array}$ & $\begin{array}{l}24 \cdot 58 \\
24 \cdot 78 \\
0 \cdot 362 \\
\text { NS }\end{array}$ & $\begin{array}{l}3 \cdot 12 \\
3 \cdot 19 \\
0 \cdot 168 \\
\text { NS } \\
\text { g.l. }=203\end{array}$ & $\begin{array}{l}23 \cdot 31 \\
23 \cdot 19 \\
0 \cdot 254 \\
\text { NS }\end{array}$ & $\begin{array}{l}16 \cdot 57 \\
15 \cdot 22 \\
1 \cdot 395 \\
\text { NS }\end{array}$ \\
\hline
\end{tabular}




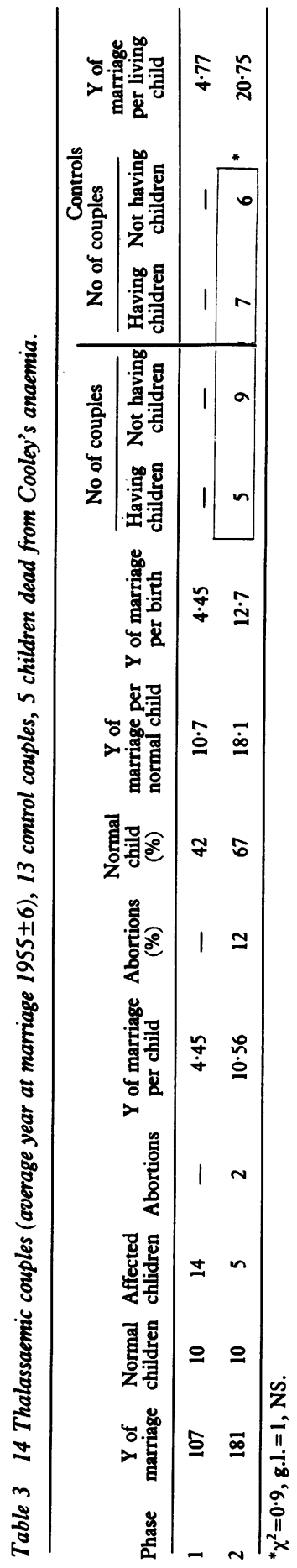

difference in the YMC index in thalassaemic and control couples (table 3). All thalassaemic couples were made aware of their risk after the birth of an affected child. In phase 2 the number of thalassaemic couples who reproduced (box in table 3 ) had more children than the corresponding control couples and therefore a lower YMC index.

Over their whole reproductive life, the mean number of children per couple was 2.79 in thalassaemic and 2.23 in control couples $(t=1 \cdot 19$, NS). The number of families was probably too small to show a significant difference. However, the difference is marked and it suggests compensation in older couples.

\section{COUPLES WHO WENT THROUGH PHASES 1, 2, AND 3 (84 COUPLES)}

The mean year of marriage was 1966 . In phase 1, before knowledge of the risk, these couples had higher reproductive activity than controls, as shown by the lower YMC index (table 4) and higher number of couples who had reproduced (box in table 4, phase 1). Knowledge of the risk occurred at the birth of an affected child in $89 \%$ of the families. In phase 2 the YMC index in thalassaemics $(25.8)$ is about twice that of controls $(14 \cdot 40$, table 4$)$ and the number of couples who did not reproduce is significantly higher than that of controls (box in table 4, phase 2). Seven out of $32(21 \cdot 8 \%)$ pregnancies were voluntarily terminated and 13 out of $25(52 \%)$ children born in this phase had Cooley's anaemia.

In phase 3 the YMC index is still higher in thalassaemic couples (table 4), but there is no difference in the number of couples who reproduced compared to control couples (box in table 4, phase 3). Nine of 18 pregnancies were voluntarily terminated without requesting prenatal diagnosis. Seven couples, one of whom had two pregnancies, selected the option of prenatal diagnosis in the eight pregnancies and of seven babies, six were normal. The affected one was born to a couple who refused abortion for ethical reasons. Over the whole reproductive life of the couples, the mean number of children per couple was 1.83 and 1.69 for thalassaemic and control couples respectively $(t=1 \cdot 22$, NS).

Among the 77 couples who did not reproduce in spite of the availability of prenatal diagnosis, the following reasons were given: presence of a normal child in addition to the affected one $(55.8 \%)$, care of the affected child (20.8\%), advanced age of the couple $(11 \cdot 7 \%)$, fear of a wrong diagnosis $(7 \cdot 8 \%)$, unacceptability of abortion (3.9\%).

COUPLES WHO WENT THROUGH PHASES 1 AND 3 (11 COUPLES)

The mean year of marriage was 1976. Those couples who started reproducing without knowledge of the 

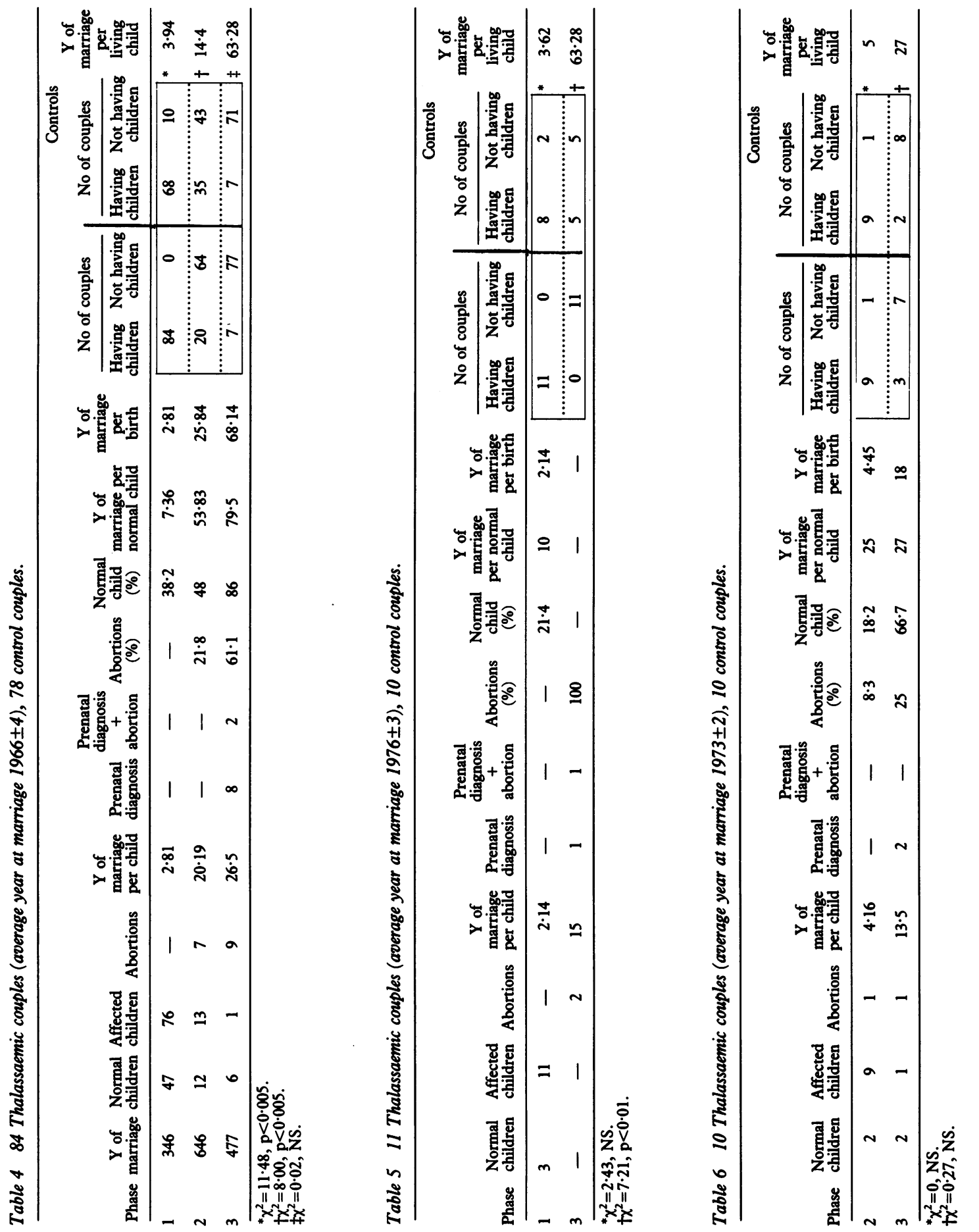


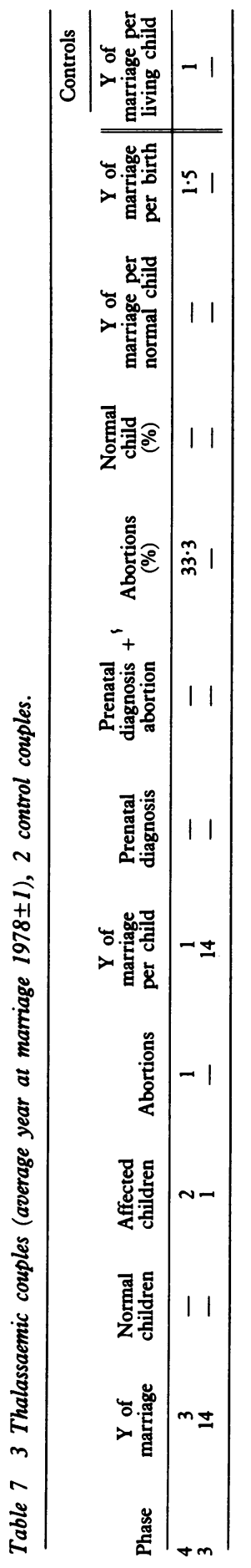

risk and were made aware of it after the birth of an affected child had a YMC index lower than that of control couples in phase 1 (table 5). The number of couples who reproduced was similar to that of control couples (box in table 5, phase 1).

In phase 3 , three pregnancies were started and all were voluntarily terminated, only one of which was after prenatal diagnosis of an affected fetus (table 5). The performance of thalassaemic couples in this phase is significantly different from control couples (box in table 5, phase 3). From the date of marriage, the mean number of children per couple was 1.27 in thalassaemic and 1.50 in control couples $(t=0.89, \mathrm{NS})$.

These 11 couples gave the following reasons for not having reproduced during the period of investigation: presence of a normal child in the family $(20 \%)$, care of the affected child (40\%), advanced age of spouses $(10 \%)$, fear of a wrong diagnosis $(30 \%)$.

\section{COUPLES WHO WENT THROUGH PHASES 2 AND 3}

(10 COUPLES)

The mean year of marriage was 1973. During phase 2 these couples, whose reproductive life started after the knowledge of their risk, have a YMC index similar to that of control couples (table 6); the number of couples who reproduced is not different from that of control couples (box in table 6, phase 2).

In phase 3 there were four pregnancies. Two of the couples requested prenatal diagnosis and healthy children were born, one couple chose abortion without prenatal diagnosis, and one couple refused abortion and had an affected child. The number of couples who reproduced did not differ from that of control couples (box in table 6, phase 3).

In both phases 2 and 3 , the mean number of children per couple was 1.4 and 1.2 respectively for the thalassaemic and control couples $(t=0 \cdot 78$, NS).

Eight of the couples so far have not requested prenatal diagnosis and gave the following reasons: presence of a normal child (12.5\%), care of the affected child (37.5\%), fear of a wrong diagnosis (25\%), unacceptability of abortion (25\%).

COUPLES WHO WENT THROUGH PHASES 4 AND 3 (PHASE 4 MAY HAVE STARTED BEFORE PHASE 3)

Three couples only passed through these phases. These couples learnt of their reproductive risk during a pregnancy when prenatal diagnosis was available; all couples refused prenatal diagnosis and in two cases an affected child was born (table 7). In the following years none of these couples requested prenatal diagnosis.

COUPLES WHO WENT THROUGH PHASE 3 ONLY (ONE COUPLE)

The affected child was born to this couple after an erroneous prenatal diagnosis performed abroad. 


\section{Discussion}

Aguzzi et $a l^{5}$ and Modell et $a l^{6}$ studied the reproductive behaviour in families segregating for Cooley's anaemia. The first study was in the same area as the present study and included couples who had reproduced from 1954 to 1974 . The second study was on immigrants to Britain from Cyprus and included couples who had reproduced from 1974 to 1979 . Both studies showed that cultural factors, among them the family size desired, influence reproductive behaviour. In the last 10 years cultural factors have changed considerably in the Po Delta area. This led us to re-examine in this area the reproductive behaviour of a group of families segregating for Cooley's anaemia before and after the availability of prenatal diagnosis.

Our survey shows partly changed reproductive behaviour in couples with heterozygous $\beta$ thalassaemia related to the social and cultural changes. These couples, during the phase of marriage when they did not know their risk (phase 1), have a lower YMC than that of control couples. Although this difference is not significant, it is suggestive of a higher reproductive rate in thalassaemic couples.

The reproductive compensation observed after knowledge of the risk in couples married in the earlier part of the period considered (mean year of marriage 1955) confirms the observations of Aguzzi et al. ${ }^{5}$ At that time, the short lifespan of the affected child, generally less than 10 years, encouraged the couples to continue reproduction to replace the affected child. In this way they reached the desired family size, that is, more than two children per couple. In contrast, the knowledge of the risk led to a marked decrease in reproduction in the couples who married later (after 1966).

Many factors could have led to this behaviour. After 1970 the cultural level in the population of the Delta area improved both educationally and economically. During the same period the birth rate in the general population decreased by $50 \%$ and the mean number of children per couple dropped to 1.5 ; this occurred not only in the Po Delta area but in the whole of northern Italy. It is possible that the improved cultural background made the understanding and use of genetic counselling easier. In addition, the mean lifespan of patients with Cooley's anaemia, limited to less than 10 years before 1970 , increased progressively because of better transfusion and chelation therapy. Now the lifespan of these patients is usually more than 20 years and the quality of their life is much improved. ${ }^{2}$ We believe therefore that the markedly decreased reproduction rate found in couples married in the 1970s is the result of a combination of cultural factors, the smaller family size desired, and the better quality of life of the affected child.

The year 1978 marks a further milestone in the history of the couples at risk. Abortion became legal and prenatal diagnosis was made available. The availability of prenatal diagnosis led to increased reproductive activity in some families who had discontinued reproduction after learning of the risk of having an affected child (couples of phases 1-2-3). It also encouraged reproduction in those couples who knew the reproductive risk before marriage but nevertheless had an affected child (couples of phases $2-3)$. However, some of the families in this study (couples of phases 1-3 and 4-3) did not want prenatal diagnosis and continued to abstain from reproducing.

These results can be seen better in the figure, where the years of marriage necessary to produce a birth are given as a function of the type of couple and of phase in each group.

However, it emerges clearly that there is not yet full awareness of the potential of prenatal diagnosis in those couples who started reproduction in phase 3. Out of 30 pregnancies in this phase, 13 were terminated without prenatal diagnosis, three were terminated after diagnosis, and nine were continued after diagnosis, one of them positive for Cooley's anaemia. This last pregnancy was continued because the prenatal diagnosis, performed abroad, was erroneous.

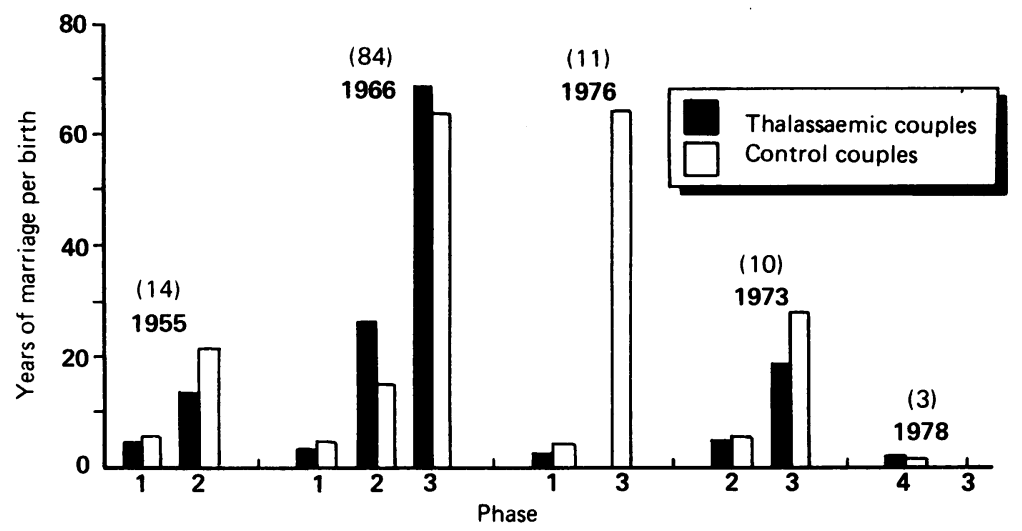

Years of marriage per birth as a function of type of couple and phase in each group. The number in parentheses is the number of couples passing through the indicated phases; the year is the average year of marriage for that group. The bar is not drawn when the couples had no children. 
Five other pregnancies, in couples who were aware of the risk and of the availability of prenatal diagnosis, but who refused it on religious grounds, resulted in the birth of a baby with Cooley's anaemia. Four were included in the present sample because of the birth of that affected child; one was included because of a previous affected child.

As a consequence of 11 prenatal diagnoses performed in this programme, eight normal and no affected children were born. It appears that the available services have the potential to control the incidence of Cooley's anaemia in this area completely. We noted also that the increased rate of reproduction after the availability of prenatal diagnosis was not as marked in our couples with an affected child as in Cypriot couples living in England. ${ }^{6}$ There may be two reasons for this. First, there may be cultural differences between the two populations and, secondly, the criteria of sample selection were different. Modell $e t$ at examined couples who had chosen prenatal diagnosis, whereas we examined couples who had an affected child.

\section{Conclusions}

There are two main indications resulting from this investigation.

(1) The couples with heterozygous $\beta$ thalassaemia, before knowledge of the risk, appeared to have a higher reproductive rate than that of control couples. (2) The knowledge of the genetic risk had a different effect on reproductive behaviour in the 1950s from that in subsequent years. We believe that this is the result of both the influence of cultural factors and technical, therapeutic, and diagnostic advances.

This work was supported by the Progetto di Ricerca Finalizzato della Regione Emilia Romagna, Contratto No 60 to the Divisione Pediatrica, USL 31 Ferrara, and by the MPI $60 \%$ and $40 \%$ funds to the Institute of Zoology, University of Ferrara.

1 Vullo C, Di Palma A, Atti G, Luciani L. Il rilievo della patologia cranica nella pratica pediatrica. Crescita 1985;13:27-32.

2 Vullo C, Argiolu F, Borgatti L, et al. The destiny of patients affected by thalassaemia major. Riv Ital Pediatr 1988;14: 553-64.

3 Weatherall DJ, Clegg JB. The thalassaemia syndromes. Oxford: Blackwell Scientific Publications, 1981.

4 Barrai I, Vullo C. Assessment of prospective genetic counseling in the Ferrara area. Am $\mathcal{F}$ Med Genet 1980;6:195-204.

5 Aguzzi S, Vullo C, Barrai I. Reproductive compensation in families segregating for Cooley's anaemia in Ferrara. Ann Hum Genet 1978;42:153-9.

6 Modell B, Ward RHT, Fairweather DVI. Effect of introducing antenatal diagnosis on reproductive behaviour of families at risk for thalassaemia major. $\mathrm{Br}$ Med $\mathcal{F} 1980 ; 280: 1347-50$.

7 Istituto Centrale di Statistica (ISTAT). Roma: Annuario Statistico Italiano Edizione, 1983. 